\title{
Collection and Preliminary Evaluation of Sweet-Stalk Pearl Millet (Pennisetum) ${ }^{1}$
}

\author{
S. Appa Rao, M. H. Mengesha, and V. Subramanian ${ }^{2}$
}

\begin{abstract}
During a germplasm collecting expedition to Tamil Nadu, India, sweet-stalk types of pearl millet, Pennisetum americanum, were collected around Coimbatore $\left(11^{\circ} \mathrm{N}\right)$ and Madurai $\left(10^{\circ} \mathrm{N}\right)$. The local farmers cut the crop before flowering for fodder and the ratoon crop provides some grain and straw. When planted at the International Crops Research Institute for the Semi-Arid Tropics Center, Patancheru $\left(17^{\circ} 30^{\prime} \mathrm{N}\right)$, these types flowered later and grew relatively tall in the rainy season in comparison with their growth during postrainy season. The sweet-stalk types are characterized by long narrow leaf blades; profuse nodal tillering with asynchronous maturity, short thin spikes, and very small grains as compared with the normal types. The sweet-stalk types could be easily identified by chewing them at the dough stage. At maturity they contained more than twice the amount of soluble sugars than the normal types.
\end{abstract}

Pearl millet, Pennisetum americanum (L.) Leeke, is primarily grown as a grain crop in Africa and Asia and as a forage crop in the United States. The world collection of pearl millet assembled in India by Rachie (1965) was evaluated for 39 characters involving vegetative, spike, and seed characters and resistance to major diseases and pests as well as resistance to drought (Murty et al., 1967). The crop as a whole shows enormous variation in the size and shape of the spikes, size and color of the seeds, amount of bristle development, glume color and several-other characters (Burton and Powell, 1968; Rachie and Majmudar, 1980). Unfortunately the world collection assembled in India has been contaminated and modified by allogamy; this was why Harlan (1973) suggested that a new start should be made. Hence, ICRISAT started collecting pearl millet germplasm systematically in priority areas of collection.

During the course of one such germplasm collecting expedition in Tamil Nadu, India, pearl millet cultivars with sweet stalks were collected. Pearl millet is planted in June-July, immediately after the onset of the southwest monsoon. It is normally intercropped with a pulse crop and is usually grown without irrigation and the application of fertilizers. The sweet-stalk pearl millet is used as a fodder which is usually harvested in September, and a subsequent ratoon crop can be taken for grain and straw. The farmers consider the straw to be superior to others because of the sweet stalks. There is an apparent dearth of information on sweetstalk pearl millet, and this paper therefore deals with their collection and characterisation.

\footnotetext{
${ }^{1}$ Received 29 June 1981; accepted 19 November 1981.

Submitted as J.A. No. 177 by the International Crops Research Institute for the Semi-Arid Tropics (ICRISAT).

${ }^{2}$ Botanist, Leader Genetic Resources, and Biochemist, respectively, International Crops Research Institute for the Semi-Arid Tropics, Patancheru, Andhra Pradesh 502 324, India.
} 


\section{MATERIALS AND METHODS}

In collaboration with Tamil Nadu Agricultural University, Coimbatore, ICRISAT collected 200 accessions of pearl millet from important millet-growing areas in Tamil Nadu during April 1978 (Appa Rao, 1978). While these seed samples were being collected, information on special characters of the local cultivars were obtained from local farmers. Sweet-stalk types were found near Pollachi, $20 \mathrm{~km}$ south of Coimbatore $\left(11^{\circ} \mathrm{N}\right)$, Aruppukottai, $30 \mathrm{~km}$ south of Madurai $\left(10^{\circ} \mathrm{N}\right)$, and Pudukkottai, $50 \mathrm{~km}$ east of Madurai. Besides the sweet-stalk types, 2 Indian (5141-A and SAR-116), and 2 west African types (D-161-C and D-128-C) were evaluated during the 1978 rainy (kharif) and postrainy ( $r a b i)$ seasons at ICRISAT Center, Patancheru $\left(17^{\circ} 30^{\prime} \mathrm{N}\right)$. Each accession was grown in $4(4 \mathrm{~m})$ rows, $75 \mathrm{~cm}$ apart with $12 \mathrm{~cm}$ between the plants. Morphoagronomical characters were scored as per the descriptors proposed by Appa Rao et al. (1980). The total soluble sugars were determined by the phenol sulphuric acid method (Dubois et al., 1956).

\section{RESULTS AND DISCUSSION}

\section{Agronomic evaluation}

The sweet-stalk types have long narrow leaves, profuse nodal tillering, small thin spikes with small grains (Fig. 1), as compared with the normal types. During the kharif season, they grew relatively tall and flowered later. However, during the rabi season, fiowering commenced earlier and growth was reduced as compared with growth during the kharif season (Table 1). This was due to differences in temperature and day length between the 2 seasons. It is known in pearl millet that time to anthesis can be reduced by imposing short days (Hellmars and Burton, 1972; Ong and Everard, 1979), and that low temperature decreases plant height (Fussell et al., 1980). The moderate photoperiod sensitivity (Burton, 1965) delays flowering in June plantings and enables these cultivars to utilize fully the scanty rainfall received during the southwest and northeast monsoons.

\section{Total soluble sugars}

In both sweet and normal types, sugar content increased up to a few days after flowering, which occurred between 65 and 80 days (Table 2). Up to flowering time soluble sugars were about the same in both types. However, at maturity the levels of the normal type decreased abruptly whereas only a slight drop was observed in the sweet-stalk types. The mean of the 4 accessions in each group is shown in Fig. 2, where the sugar content is plotted against days after sowing. The differences in sugar content at maturity were verified in the kharif season 1979. Though seasonal variation in sugar content was observed, sweet-stalk types were found to contain more than twice the amount of soluble sugars found in the normal types. The stem of pearl millet was considered to serve as a store of assimilates for the developing grain, as the soluble carbohydrates in the stem declined sharply during early grain-filling stage (Fussell et al., 1980). It appears that more sugars are translocated from the stalks to the grain in the normal types as compared with the sweet-stalk types. This is particularly apparent in the cultivar D-161-C that had the biggest grain and showed the highest sugar content at flowering and the minimum at maturity. It is similar to the situation that exists 


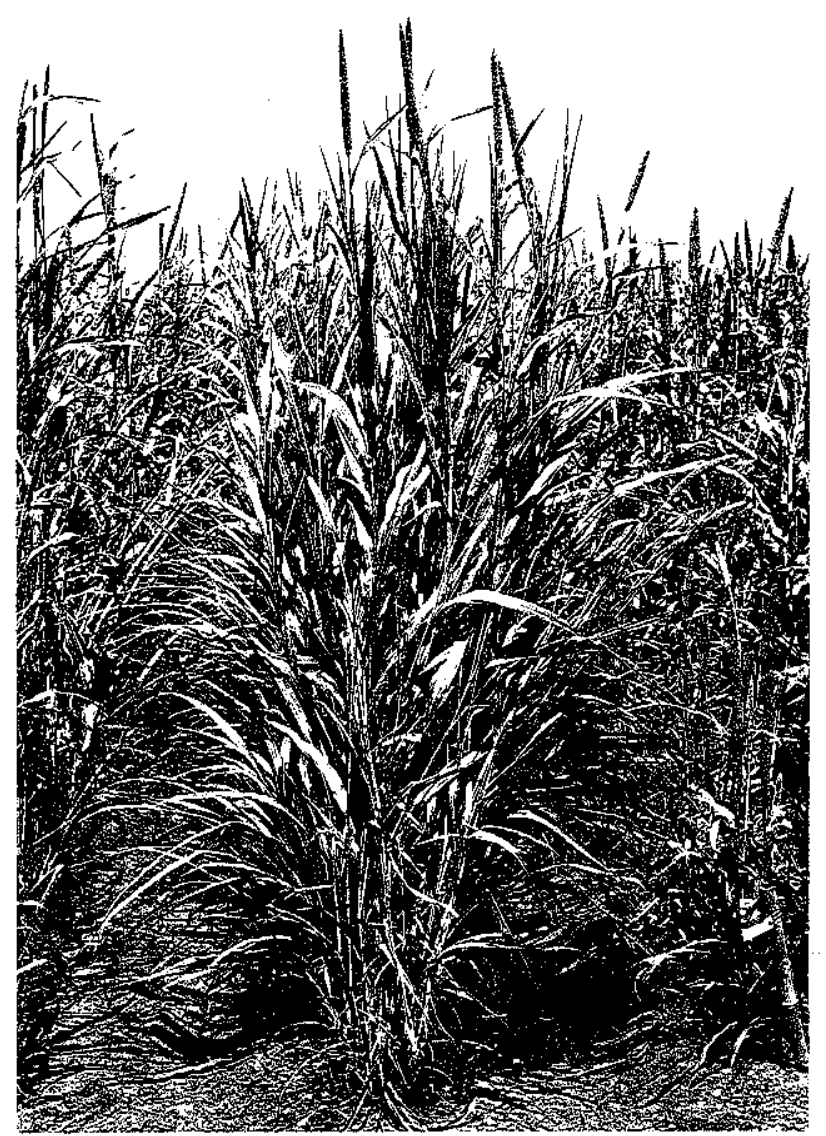

Fig. 1. Sweet-stalk pearl millet with profuse nodal tillering, long narrow leaves and small spikes.

TABLE 1. RANGE AND MEANS OF AGRONOMICAL CHARACTERS OF SWEET- AND NORMALSTALK PEARL MILLET.

\begin{tabular}{|c|c|c|c|c|c|c|c|c|c|c|c|c|c|}
\hline \multirow[b]{3}{*}{ Identity } & \multicolumn{2}{|c|}{$\begin{array}{l}\text { Days to } 50 \% \\
\text { flowering }\end{array}$} & \multicolumn{4}{|c|}{$\begin{array}{l}\text { Plant height } \\
\text { (cm) }\end{array}$} & \multirow{2}{*}{\multicolumn{2}{|c|}{$\begin{array}{l}\text { Stem thick- } \\
\text { ness (mm) }\end{array}$}} & \multirow{2}{*}{\multicolumn{2}{|c|}{$\begin{array}{l}\text { Leaf length } \\
\quad(\mathrm{cm})\end{array}$}} & \multirow{2}{*}{\multicolumn{2}{|c|}{$\begin{array}{l}\text { Spike length } \\
\text { (cm) }\end{array}$}} & \multirow{3}{*}{$\begin{array}{c}1,000 \\
\text { grain } \\
\text { weight } \\
\text { (g) }\end{array}$} \\
\hline & \multirow{2}{*}{$\begin{array}{l}\text { Kharif } \\
\text { season }\end{array}$} & \multirow{2}{*}{$\begin{array}{l}\text { Rabi } \\
\text { sea- } \\
\text { son } \\
\end{array}$} & \multicolumn{2}{|c|}{ Kharif } & \multicolumn{2}{|l|}{ Rabi } & & & & & & & \\
\hline & & & Range & Mean & Range & Mean & Range & Mean & Range & Mean & Range & Mean & \\
\hline \multicolumn{14}{|c|}{ I. Sweet-stalk types } \\
\hline SAR-696 & 81 & 70 & $280-400$ & 330 & $100-145$ & 130 & $8-10$ & 9.2 & $60-75$ & 64 & $15-25$ & 21.4 & 5.40 \\
\hline SAR-713 & 99 & 72 & $310-430$ & 366 & $110-140$ & 135 & $8-11$ & 8.9 & $65-78$ & 73 & $21-38$ & 31.0 & 7.20 \\
\hline SAR-763 & 106 & 74 & $300-410$ & 348 & $115-160$ & 150 & $7-10$ & 8.8 & $51-67$ & 59 & $19-25$ & 23.1 & 4.80 \\
\hline SAR-856 & 92 & 71 & $280-410$ & 358 & $100-140$ & 130 & $8-09$ & 8.5 & $60-75$ & 68 & $22-35$ & 29.7 & 5.50 \\
\hline \multicolumn{14}{|c|}{ II. Normal-stalk types } \\
\hline 5141-A & 59 & 54 & $135-160$ & 145 & $85-115$ & 97 & $8-09$ & 8.6 & $40-50$ & 48 & $18-23$ & 21.0 & 7.00 \\
\hline D-161-C & 71 & 77 & $175-300$ & 216 & $290-310$ & 300 & $9-11$ & 9.8 & $62-74$ & 66 & $34-50$ & 42.6 & 12.30 \\
\hline Jakhrana & 49 & 61 & $200-210$ & 205 & $170-180$ & 175 & $8-09$ & 8.8 & $47-62$ & 52 & $25-43$ & 31.4 & 7.10 \\
\hline D-128-C & 68 & 78 & $230-310$ & 263 & $200-255$ & 229 & $9-11$ & 10.2 & $60-70$ & 64 & $30-70$ & 39.5 & 8.20 \\
\hline
\end{tabular}




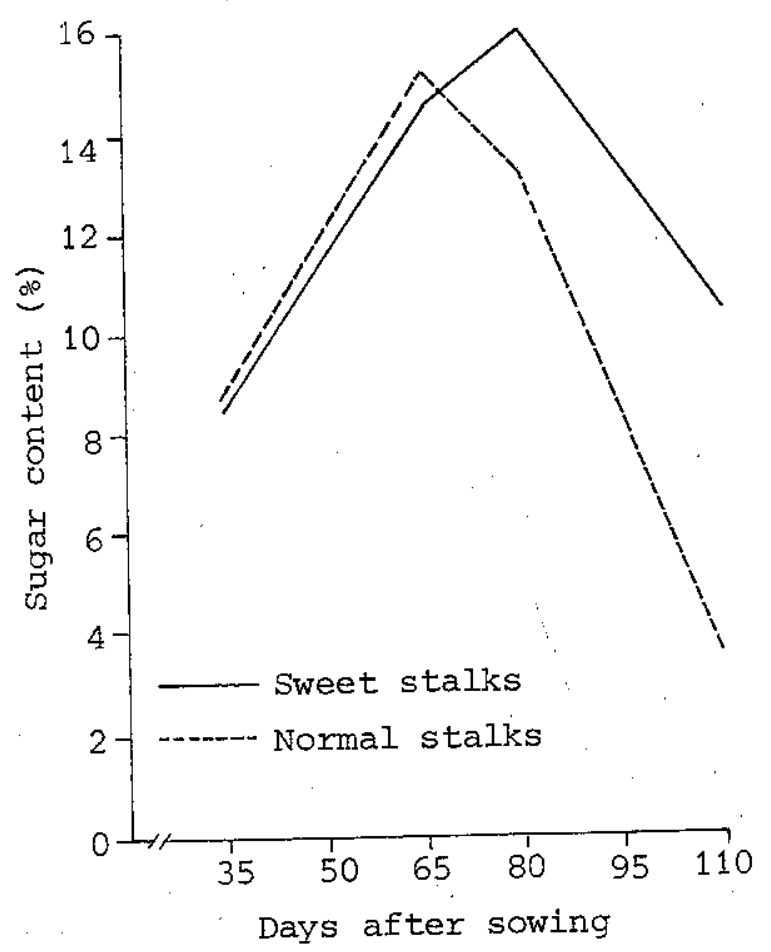

Fig. 2. Changes in mean sugar content between normal and sweet-stalk pearl millet at different stages of growth.

in sorghum. Wall and Blessin (1970) reported that the stalks of sweet sorghums contained $21 \%$ soluble sugars, whereas grain sorghums contained $5-6 \%$ only. The wild relatives of sorghum, sugarcane and maize have low soluble sugars in their stalks, while some of the cultivated types have high amounts of soluble sugars, indicating parallel evolution.

TAble 2. Changes in soluble sugar CONTENT in Stalks of PEARL Millet. ${ }^{\text {a }}$

\begin{tabular}{|c|c|c|c|c|}
\hline \multirow[b]{2}{*}{ Pedigree } & \multicolumn{4}{|c|}{ Sugar content in \% (oven-dry basis) } \\
\hline & 35 days & 65 days & 80 days & 110 days \\
\hline & \multicolumn{4}{|c|}{ Sweet-stalk types } \\
\hline SAR-696 & 11.56 & 17.96 & 13.26 & 11.91 \\
\hline SAR-713 & 5.42 & 11.03 & 19.74 & 10.97 \\
\hline SAR-763 & 8.72 & 11.73 & 17.93 & 8.56 \\
\hline \multirow[t]{2}{*}{ SAR-856 } & 8.37 & 17.42 & 13.47 & 10.97 \\
\hline & \multicolumn{4}{|c|}{ Normal-stalk types } \\
\hline 5141-A & 10.26 & 13.77 & 4.94 & 3.42 \\
\hline D-161-C & 6.48 & 19.41 & 20.11 & 2.28 \\
\hline Jakhrana & 10.86 & 12.43 & 13.31 & 5.14 \\
\hline D- $128-C$ & 7.12 & 15.43 & 14.48 & 4.23 \\
\hline
\end{tabular}

\footnotetext{
a Planted on 20 June 1979.
} 
The high sugar content in the mature stalks apparently makes them sweet, as can be identified by chewing them at the dough stage onward. The sweet-stalk types appear to be good fodder types, because fodder yield had been shown to be mainly dependent on tiller number, leaf number and size, plant height, maturity, and stem thickness (Gupta and Sidhu, 1973). As the sweet-stalk types can be easily identified by chewing, the world collection will be screened and selection made for an increase in sugar content.

\section{ACKNOWLEDGMENTS}

Thanks are due to Professor R. Appadurai and his colleagues, Tamil Nadu Agricultural University, Coimbatore, India, for their help and collaboration in collecting the seed samples, and to Mr. D. J. Andrews, Leader, Pearl Millet Improvement Program, ICRISAT, for his suggestions.

\section{LITERATURE CITED} Appa Rao, S. 1978. Collection of pearl millet from Tamil Nadu. ICRISAT Genetic Resources Progress
Report, Patancheru, Andhra Pradesh, India.

- D. J. Andrews, and M. H. Mengesha. 1980. Descriptors for pearl millet germplasm. ICRISAT Genetic Resources Progress Report-14, Patancheru, Andhra Pradesh, India.

Burton, G. W. 1965. Photoperiodism in pearl millet, Pennisetum typhoides. Crop Sci. 5: 333-335.

Dubois, and J. B. Powell. 1968. Pearl millet breeding and cytogenetics. Advances Agron. 20: 49-89.

Dubois, M., K. A. Gilles, J. K. Hamilton, P. A. Roberts, and F. Smith. 1956. Methods for determination of sugars and related substances. Analytical Chem. 28: 350-356.

Fussell, L. K., C. J. Pearson, and M. J. T. Norman. 1980. Effect of temperature during various growth stages on grain development and yield of Pennisetum americanum. J. Exp. Bot. 31: 621-633.

Harlan, J. R. 1973. Genetic resources of some major field crops in Africa. In O. H. Frankell, ed. Survey of crop genetic resources in their centres of diversity. 1st report. FAO, Rome.

Hellmars, H., and G. W. Burton. 1972. Photoperiodism and temperature manipulation induces early anthesis in pearl millet. Crop Sci. 12: 198-200.

Gupta,_V.P., and P. S. Sidhu. 1973. Selection criteria for improving green fodder yield in Pennisetum typhoides S.\&H. Plant Sci. 5: 36-38.

Murty, B. R., M. K. Upadhyaya, and P. L. Manchanda. 1967. Classification and cataloguing of a world collection of genetic stocks of Pennisetum. Indian J. Genet. Pl. Breed. 27 (Spl. No.):
313-394.

Ong, C. K., and S. Everard. 1979. Short day induction of flowering in pearl millet (Pennisetum typhoides) and its effect on plant morphology. Exp. Agric. 15: 401-410.

Rachie, K. O. 1965. The systematic collection of sorghums, millets, and maize in India. Rockefeller Foundation and the Indian Council of Agricultural Research, New Delhi.

, and J. V. Majmudar. 1980. Pearl Millet. Pennsylvania State Univ. Press, University Park,
PA, and London.

Wall, J. S., and C. W. Blessin. 1970. Composition of sorghum plant and grain. In Wall, W. S., and W. M. Ross, ed., Sorghum Production and Utilization. AVI Publishing, Westport, CT. 